\title{
A vector for systematic gene inactivation in Bacillus subtilis
}

\author{
Valérie Vagner, Etienne Dervyn and S. Dusko Ehrlich \\ Author for correspondence: Valérie Vagner. Tel: + 331346525 34. Fax: + 33134652521. \\ e-mail : vagner@biotec.jouy.inra.fr
}

Génétique Microbienne, Institut National de la Recherche Agronomique, Domaine de Vilvert, 78352 Jouy-en-Josas cedex, France
To study the functions of the uncharacterized open reading frames identified in the Bacillus subtilis genome, several vectors were constructed to perform insertional mutagenesis in the chromosome. All the pMUTIN plasmids carry a lacz reporter gene and an inducible Pspac promoter, which is tightly regulated and can be induced about 1000-fold. The integration of a pMUTIN vector into the target gene has three consequences: (1) the target gene is inactivated; (2) lacz becomes transcriptionally fused to the gene, allowing its expression pattern to be monitored; (3) the Pspac promoter controls the transcription of downstream genes in an IPTG-dependent fashion. This last feature is important because $B$. subtilis genes are often organized in operons. The potential polar effects generated by the integration of the vectors can be alleviated by addition of IPTG. Also, conditional mutants of essential genes can be obtained by integrating pMUTIN vectors upstream of the target gene. The vectors are currently being used for systematic inactivation of genes without known function within the B. subtilis European consortium. pMUTIN characteristics and the inactivation of eight genes in the resA-serA region of the chromosome are presented.

Keywords: integrational vector, Bacillus subtilis, inducible promoter, essential genes

\section{INTRODUCTION}

The last 2 years have been marked by the release of complete nucleotide sequences of several unicellular organisms. In addition to the seven bacterial genomes already available, the sequence of the Bacillus subtilis chromosome is now complete (Kunst et al., 1997). Among the 4000 URFs (unknown reading frames; Doolittle, 1998) identified in B. subtilis, $26 \%$ show no significant homology to sequences in the databases, $12 \%$ show homology to unknown genes in other organisms and only about 1000 have been characterized experimentally (Kunst et al., 1997). Systematic transcriptional analysis carried out on a region of the chromosome indicates that most of the newly identified genes can be expressed (Azevedo et al., 1993).

The function of newly discovered genes can be studied by destruction techniques followed by the monitoring of the effect on cell fitness under different growth conditions. In some cases, sequencing and gene-disruption techniques have been combined (e.g. Drosophila melanogaster; Spradling et al., 1995). In Rhodobacter

The GenBank accession number for PMUTIN2 is AF072806. capsulatus, a defective transducing phage which packages DNA fragments has been used to replace target genes with an antibiotic-resistance marker (Kumar et al., 1996). In Saccharomyces cerevisiae, gene disruptions have been performed en masse by random insertional mutations using Ty1 (Smith et al., 1995). In Escherichia coli, a gene-replacement strategy has been used with a vector containing a temperature-sensitive origin of replication. An in vitro-altered sequence is introduced in the genome by recombination with the vector which is then excised at the permissive temperature. The resulting structure is an in-frame deletion without polar effects on downstream genes (Link et al., 1997).

Recently, a number of laboratories have pooled their expertise to analyse the thousands of newly discovered genes, in the context of two European function analysis projects. In the case of $S$. cerevisiae, 1000 unknown genes are beeing analysed by a European consortium (EUROFAN), involving 144 laboratories (Oliver, 1996). A gene-by-gene replacement strategy has been chosen, which involves the insertion of a kanamycin-resistance gene flanked by PCR fragments (Oliver, 1996; Shoemaker et al., 1996). 
A similar project has been started in B. subtilis, within a network of 18 European laboratories that share a common approach to inactivate about 1200 new genes. A parallel network of 12 Japanese laboratories has adopted the same approach (N. Ogasawara, personal communication). A gene-by-gene inactivation procedure has been chosen, using the set of vectors described here. These vectors combine various elements which have been previously developed in integrational plasmids (Perego, 1993). Their main properties are: (i) an inability to replicate in $B$. subtilis, which allows insertional mutagenesis; (ii) a reporter $l a c Z$ gene, to facilitate the measurement of the expression of the target gene; (iii) an inducible promoter to allow controlled expression of genes downstream of, and found in the same operon as, the target gene. This last requirement has been motivated by the observation that most of the genes in the B. subtilis genome are organized in multicistronic units. Any insertion in an operon separates downstream genes from their promoter, which may lead to failure to express these genes. Such polar effects are not desirable when studying a unique gene function. In addition, our strategy makes it possible to create conditional mutants, where the target gene expression is regulated by the inducible promoter. The inducible Pspac promoter, developed by Yansura \& Henner (1984), has been chosen for this purpose and has been modified to allow better control of the promoter activity. The use of the vectors is illustrated by the inactivation of eight genes of unknown function in the resA-lys $A$ region of the $B$. subtilis chromosome.

\section{METHODS}

Strains and growth conditions. The B. subtilis 168 (trpC2) strain was provided by C. Anagnostopoulos (INRA, Jouy-enJosas, France). The HVS320 strain is a 168 derivative (trpC2 tyrA1 aroB2 his $\mathrm{H} 2 \mathrm{Cm}^{\mathrm{R}}$ ) carrying pBR322 sequences inserted in the chromosome close to the metB locus (Vagner $\&$ Ehrlich, 1988). The HVS597 strain is a B. subtilis 168 strain containing the $d n a C$ gene under the control of the Pspac promoter by insertion of pMUTIN2 in front of the gene, as described below. Primers used for the amplification of the target sequence are described in Table 1.

Plasmids were prepared in E. coli MC1061. Luria-Bertani (LB) medium was used for cultures of $B$. subtilis and $E$. coli (Miller, 1972). Minimal medium for B. subtilis and transformation methods have been described previously (Anagnostopoulos \& Spizizen, 1961). Antibiotics were used at the following concentrations: $0 \cdot 3 \mu \mathrm{g}$ erythromycin $\mathrm{ml}^{-1}$ for $B$. subtilis and $100 \mu \mathrm{g}$ ampicillin $\mathrm{ml}^{-1}$ for E. coli.

DNA extraction and manipulation. Restriction enzymes were used as recommended by the supplier. Polymerase chain reactions (PCR) were carried out with Taq polymerase (Boehringer), according to the conditions described by the manufacturer using the following programme: $5 \mathrm{~min}$ at $94{ }^{\circ} \mathrm{C}$ then 30 cycles of $30 \mathrm{~s}$ at $94^{\circ} \mathrm{C}, 30 \mathrm{~s}$ at $50^{\circ} \mathrm{C}$ and then $1 \mathrm{~min}$ at $72{ }^{\circ} \mathrm{C}$.

Plasmid DNA was isolated from $E$. coli by the alkaline lysis method (Birnboim \& Doly, 1979). Chromosomal DNA was extracted from B. subtilis as described by te Riele et al. (1986). Structures formed upon integration were verified by Southern blot hybridization on Hybond- $\mathrm{N}^{+}$filters (Amersham), after
EcoRV chromosomal digestion. DNA probes were labelled and hybridized with the enhanced chemiluminescence direct nucleic acid labelling and detection system (Amersham).

Construction of the vectors. A XbaI-BamHI fragment containing the $\mathrm{Em}^{\mathrm{R}}$ gene from pVE6023 (E. Maguin, personal communication) and the EcoRI fragment from pDG148 (Stragier et al., 1988) containing the $\beta$-lactamase gene, the replication origin from ColE1, the E. coli lacl gene, and the Pspac promoter, were filled by the Klenow enzyme and ligated together. The lacZ gene flanked by a spoVG ribosome-binding site (RBS) was isolated from pJM783 (Perego, 1993) after a BamHI/DraI digestion. This fragment, treated by the Klenow enzyme, was cloned in the blunted SphI site of the previous plasmid in the same orientation as lacl gene. The $\lambda$ terminator $\mathrm{t}_{0}$ was isolated after a PCR amplification with the pSS9 vector (Scholtissek \& Grosse, 1987) using primers 5' GCTCTAGACCCGGGGATCTCTGCAG $3^{\prime}$ and $5^{\prime}$ GCTCTAGAGCAACGTTCTTGCCATT 3' carrying a Xbal restriction site (shown in italics). The PCR product was cloned in the $X b a I$ site of the plasmid. In the resulting pMUTIN1 vector, the $\lambda$ terminator $\left(t_{0}\right)$ stops transcription from the $\mathrm{Em}^{\mathrm{R}}$ gene.

The pMUTIN2 vector was generated by the cloning of $t_{1} t_{2}$ terminators from the $r r n B$ operon of $E$. coli, known to be active in B. subtilis (Peschke et al., 1985), upstream of $\lambda t_{0}$. They were isolated after a PCR amplification using primers 5' GGAAGATCTTCATCACCGAACGCGGCAGGC $3^{\prime}$ and $5^{\prime}$ GGAAGATCTGGTAATGACTCTCTAGCTTGAGC ${ }^{\prime}$ with p602/22T2 as a matrix (P. Noirot, personal communication). After a BglII digestion, the amplified fragment was cloned in the NruI site of pMUTIN1.

A perfect palindromic sequence $\left(5^{\prime}\right.$ AATTGTGAGCGCT CACAATT $3^{\prime}$ ) was put in place of the $\mathrm{O} 1$ lac operator in pMUTIN1, resulting in pMUTIN3. The palindromic operator denoted 'oid' was isolated after a mutagenized PCR reaction using primers $5^{\prime}$ GCCCGATATCCTAACAGCACA 3 ' and $5^{\prime}$ GCCGAAGCTTAATTGTGAGCGGCTCACAATTCCACACA 3'. After digestion with HindIII and EcoRV (sites in italics), the PCR product was cloned within the EcoRVHindIII large fragment of pMUTIN1. The same experiment was carried out in pMUTIN2, resulting in pMUTIN4, which carries both the palindromic operator 'oid' and the $t_{1} t_{2}$ terminators.

A multicloning site HindIII-EcoRI-NotI-SacII-BamHI was introduced between the Pspac and the lacZ gene of pMUTIN2 and pMUTIN4. To do this, the oligonucleotides 5' CGCGGATCCGGCGGCCGCCCGGGAATTCAAGCTTCGGC $3^{\prime}$ plus the complementary strand were annealed, then digested with HindIII and BamHI (sites in italics). The resulting fragments were cloned in the pMUTIN2 and pMUTIN4 vectors after digestion with the same enzymes.

Construction of mutants. A fragment of the target genes was amplified from 168 chromosomal DNA by PCR with primers (Table 1), then extracted from polyacrylamide gels after electrophoresis. Products were digested with HindIII and BamHI in parallel with the pMUTIN1 (for insertion) or pMUTIN2 (for Pspac fusion). After heat inactivation of the enzymes, fragments and plasmid were mixed for ligation (ratio 10:1 molecules). The ligation mixtures were used to transform competent cells of E. coli. Recombinant plasmids were extracted and then used to transform competent cells of B. subtilis. Transformants were selected on LB plates containing $0.3 \mu \mathrm{g}$ erythromycin $\mathrm{ml}^{-1}$ and analysed by Southern blot hybridization to ensure that a single copy of the plasmid had integrated into the chromosome.

Enzymic assays. $\beta$-Galactosidase was assayed as previously 
Table 1. Primers for construction of mutants

The primers contain around 17 bp homology with the chromosome (underline), 6 bases of a restriction site (italics) and 2 or 3 additional bases for restriction improvement (bold).

\begin{tabular}{|c|c|}
\hline Gene & Primer $\left(5^{\prime} \rightarrow 3^{\prime}\right)$ \\
\hline \multicolumn{2}{|c|}{ Interruption } \\
\hline \multirow[t]{2}{*}{$y p u A$} & GCCAAGCTTGTAACACTGGGTGCTG \\
\hline & CGGGATCCGGTTTTTTCCGAGGCCT \\
\hline \multirow[t]{2}{*}{$y p u C$} & GCCAAGCTTAGAGGTGTTCTGTTAGCC \\
\hline & CGGGATCCGAACAAAAAGATAAGCAC \\
\hline \multirow[t]{2}{*}{ ypuF } & GCCAAGCTTAACGCTATTGGGTGGGCTTTA \\
\hline & CGGGATCCTGCATGCTTCCTCCAGTTT \\
\hline \multirow[t]{2}{*}{$y p u G$} & GCCAAGCTTGAGCTCGACATTG \\
\hline & CGGGATCCTTTCTTCTTCCCGTTC \\
\hline \multirow[t]{2}{*}{ ypuH } & GCCAAGCTTGAAATCGAAGAGC \\
\hline & CGGGATCCAGATGCTTGAGAAGGC \\
\hline \multirow[t]{2}{*}{ ypul } & GCCAAGCTTGGGACATTCGATTGTG \\
\hline & CGGGATCCGAAAAGGCTCCTGCATCA \\
\hline \multirow[t]{2}{*}{$y p u L$} & GCCAAGCTTGCTCATGCCGGAGTTG \\
\hline & CGGGATCCGTCACCACTTTGCG \\
\hline \multicolumn{2}{|l|}{ Fusion } \\
\hline \multirow[t]{2}{*}{$y p u D$} & GCCAAGCTTGGAGGTTTAGAAATGGG \\
\hline & CGGGATCCGAAGATGATTTTCGTTCCG \\
\hline \multirow[t]{2}{*}{$y p u G, H$} & GCCAAGCTTGAAAATGGTGAGATGATGG \\
\hline & CGGGATCCTTTCTTCTTCCCGTTC \\
\hline \multirow[t]{2}{*}{$d n a C$} & GCCAAGCTTGGAGATTTTTTAATGAGAG \\
\hline & CGGGATCCGCGATATCAGTCAAATA \\
\hline
\end{tabular}

described (Msadek et al., 1990). $\beta$-Galactosidase activity was expressed in Miller units (mg protein) ${ }^{-1}$ (Miller, 1972). Protein concentrations were determined using the Bio-Rad Protein Assay kit.

\section{RESULTS AND DISCUSSION}

\section{PMUTIN: an integrational vector in B. subtilis}

The prototype vector of the pMUTINs set (Fig. 1) has the following properties. (i) It cannot replicate in $B$. subtilis but carries ColE1 replication sequences and a $\beta$ lactamase gene $\left(\mathrm{Ap}^{\mathrm{R}}\right)$ for amplification in E. coli. An erythromycin-resistance gene $\left(\mathrm{Em}^{\mathbf{R}}\right)$ provides a selectable marker in B. subtilis. (ii) It carries the modified $E$. coli lac $Z$ reporter gene allowing transcriptional fusions and measurement of gene expression in B. subtilis (Perkins \& Youngman, 1986). For this purpose, the RBS of the spoVG gene of $B$. subtilis and stop codons in the three possible frames are present upstream of the lac $Z$ gene. (iii) It carries the Pspac inducible promoter, which contains the RNA polymerase recognition sequences of the SPO1 phage and one of the three lac operators designated 'O1' (Yansura \& Henner, 1984). (iv) It carries the lacl gene which has been modified to be constitutively expressed in $B$. subtilis. Pspac is repressed by LacI and therefore can be induced by IPTG (Yansura \& Henner, 1984). (v) A $\lambda$ terminator of transcription, $t_{0}$, is present at the end of the $\mathrm{Em}^{\mathrm{R}}$ gene.
Genes can be inactivated by inserting the pMUTIN within a gene via a single crossing-over event (Fig. 2). An internal fragment of the target gene is amplified by PCR, cloned in pMUTIN, and the resulting plasmid used to transform B. subtilis. Upon integration, the target gene is interrupted and a transcriptional fusion is generated between its promoter and the reporter lac $Z$ gene. In multicistronic organization, any gene(s) situated downstream of the target gene are placed under the control of the inducible Pspac promoter. The $\lambda t_{0}$ terminator should prevent RNA polymerase not loaded at the Pspac to transcribe downstream genes. It should be noted that the procedure presented in Fig. 2 generates simultaneously two types of mutants: a first one null (orf2) via gene interruption, and a second conditional (orf3), via IPTG dependence. The second type can also be obtained by using for integration a plasmid carrying homology with the RBS and the $5^{\prime}$ end of the target URF.

\section{Activity of the Pspac promoter in the chromosome}

The Pspac promoter has previously been extensively exploited for gene induction, either on multi-copy replicative plasmids (Barilla et al., 1994; Chang et al., 1996), or in the chromosome (Lu et al., 1995; Voelker et al., 1995). However, no reports exist concerning the activity of this promoter in a single copy on the chromosome, with or without LacI repression. We 


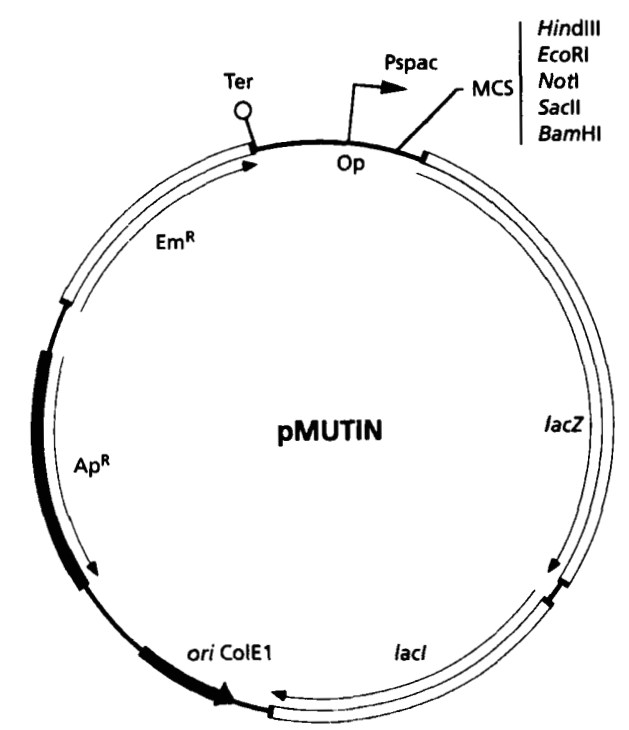

\begin{tabular}{|ccccc|}
\hline pMUTIN & $\begin{array}{c}\text { Size } \\
(\mathrm{bp})\end{array}$ & Ter & Op & MCS \\
\hline 1 & 8388 & $t_{0}$ & 01 & No \\
2 & 8611 & $t_{1} t_{2} t_{0}$ & 01 & Yes \\
3 & 8387 & $t_{0}$ & oid & No \\
4 & 8610 & $t_{1} t_{2} t_{0}$ & oid & Yes \\
\hline
\end{tabular}

Fig. 1. Map of the pMUTIN vector set. Common features of the pMUTIN vectors are presented in the figure. White boxes are for genes expressed in B. subtilis ( $\mathrm{Em}^{\mathrm{R}}$ lacl lacZ) and the black box is for the $A p^{R}$ gene expressed in $E$. coli. The black arrow represents sequences used for replication in E. coli (ColE1 ori). The broken arrow indicates the direction of transcription of the Pspac promoter. The 'Ter' element (lollipop) indicates the terminators: $\lambda t_{0}$ is present in all vectors; $t_{1} t_{2}$ are present in pMUTIN2 and pMUTIN4. 'Op' indicates the Lacl operator between the Pspac promoter sequences: the ' 01 ' operator is present in pMUTIN1 and pMUTIN2, and the 'oid' operator is present in PMUTIN3 and pMUTIN4. Differences between the pMUTINs are set out in the table below the plasmid map.

examined this by transforming the pMUTIN1 vector into a B. subtilis strain (HVS320) containing pBR322 sequences integrated in the chromosome. The integration results in a fusion between the Pspac promoter and the reporter lac Z gene (Fig. 3a). The Pspac induction was measured at different stages of growth in the presence of $1 \mathrm{mM}$ IPTG (Fig. 3b). The maximum of $\beta$ galactosidase activity during exponential growth was reached in $20 \mathrm{~min}$. Pspac induction was 10 -fold less efficient during the stationary phase. The Pspac activity was measured in different locations in the chromosome, showing no significant differences, which leads to the conclusion that there is no influence of the chromosomal environment on the promoter activity (data not shown). We also measured the induction of Pspac during exponential phase as a function of the IPTG concentration (Fig. 3c). A 200-fold induction was obtained with pMUTIN1, with $300 \mu \mathrm{M}$ IPTG in the culture. Higher concentrations of IPTG did not significantly increase the level of induction.
The $\beta$-galactosidase activity measured for pMUTIN1 without IPTG was about 10 -fold higher than that measured in the strain without pMUTIN1. This residual expression can be accounted for to some extent by readthrough from external promoters located upstream of the Pspac, and/or by a low affinity of the LacI protein for the Pspac operator. Further investigations were carried out to test these two points and to obtain a better repression of the Pspac promoter.

\section{Effects of terminators and improved operators on the promoter}

The anchoring of the Lac repressor on one of its operators $(\mathrm{O} 1)$ is directly correlated to the affinity of the protein for its operator (Straney \& Crothers, 1987). It has been shown in E. coli that maximal repression of the lac promoter is due to the cooperative effect of three operators (O1, O2 and O3; Oehler et al., 1994). The affinity of Lacl for $\mathrm{O} 1$ alone is threefold lower than for all three operators, and the replacement of $\mathrm{O} 1$ by a perfect palindromic sequence called the 'oid' operator (Lehming et al., 1987) increases repression of the lac promoter more than $2 \cdot 5$-fold. To improve the Pspac repression by Lacl binding, we substituted the $\mathrm{O} 1$ operator present in pMUTIN1 in the vicinity of Pspac by the 'oid' operator, resulting in the pMUTIN3 vector. The putative effect of upstream transcription forks on Pspac activity was tested by adding two strong terminators $\left(t_{1} t_{2}\right.$ from $\left.r r n B\right)$ close to $\lambda t_{0}$, resulting in the pMUTIN2 vector. The vector containing both the 'oid' sequence and the three terminators is designated pMUTIN4.

$\beta$-Galactosidase activity was measured after integration of these different vectors in the chromosome by recombination with pBR322 sequences as shown in Table 2 . Without IPTG, $\beta$-galactosidase activity was reduced almost to the background level when the two terminators were present (pMUTIN2 and 4), whereas it was three- to fourfold higher when the operator alone was modified (pMUTIN3). This suggests that upstream transcription at readthrough may be responsible for the $\beta$-galactosidase activity observed for pMUTIN1 and 3. However, the twofold effect of 'oid' in pMUTIN3 on Pspac repression suggests that a better anchoring of the repressor is obtained with the 'oid' operator, which also influences Pspac activity. The threefold reduction of induction by IPTG in pMUTIN4 speaks for an additive effect of the operator and the terminators in this type of structure.

\section{Use of pMUTIN for gene inactivation and controlled expression}

A region situated between $l y s A$ and $r e s A$ was chosen as an example for gene inactivation (Fig. 4). The region was previously sequenced (Sorokin et al., 1993) and analysed by Northern blotting (Azevedo et al., 1993). Twelve putative genes in this region have unknown functions and seven were chosen as candidates for disruption, because the other genes (namely $y p u E, y p u B$, 


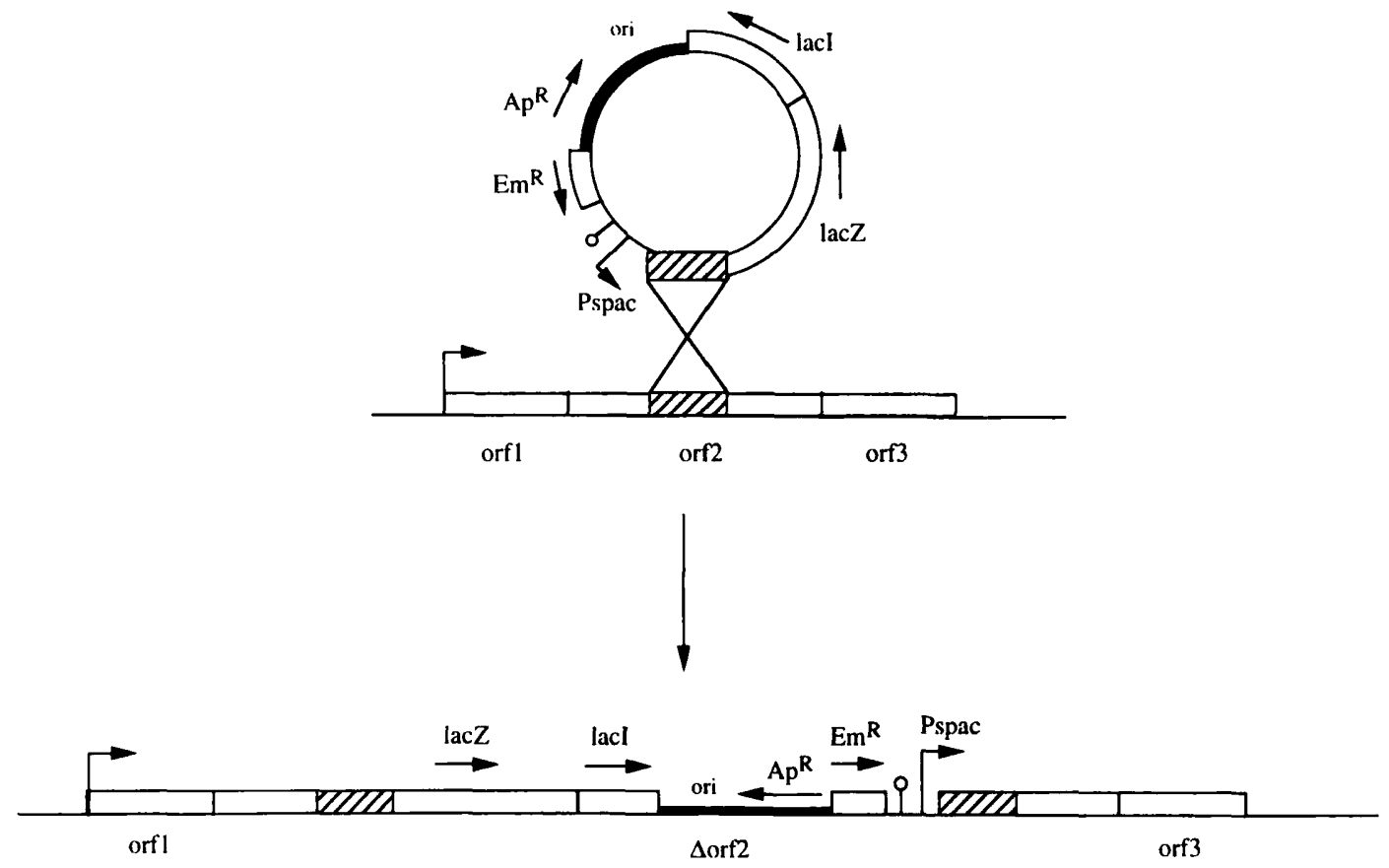

Fig. 2. Integration of pMUTIN into a target gene. Genes of the orf1-orf3 operon are indicated as white boxes. Hatched box corresponds to the internal segment of the target gene. The vector is integrated in orf 2 by a single crossing-over event. Arrows indicate direction of transcription, broken arrows denote the promoter of the operon and Pspac, and the lollipop strand is for the transcription termination.
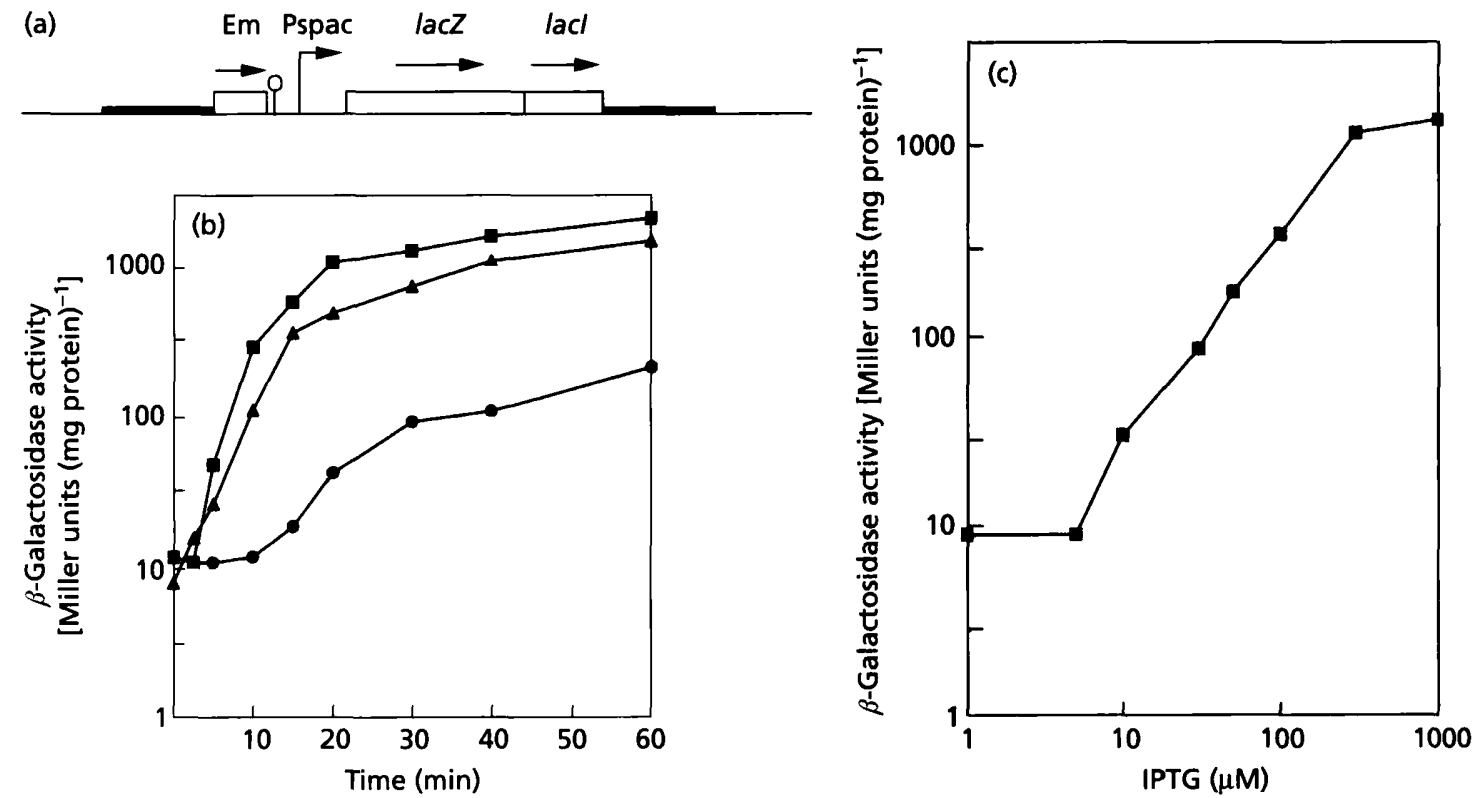

Fig. 3. (a) Structure obtained upon integration of PMUTIN into PBR322 sequences in the $B$. subtilis chromosome. The recipient strain (HVS320) contains pBR322 sequences, which are used for homologous recombination with the pMUTIN. This results in duplication of pBR322 sequences (heavy line), and a transcriptional fusion between Pspac and lacZ. (b) Induction of Pspac at different stages of cell growth. IPTG $(1 \mathrm{mM})$ was added to cultures in rich medium at $O D_{600} 0.35$ (D) 0.75 (A) or $1.3(0)$. The $\beta$-galactosidase activity was measured on cells harvested at different times after addition of IPTG. (c) Pspac activity as a function of IPTG concentration. Cells were grown in rich medium in the presence of IPTG, and harvested at $\mathrm{OD}_{600} 0.5$ before the measurement of $\beta$-galactosidase specific activity. 
Table 2. $\beta$-Galactosidase activities of pMUTIN integrants of $B$. subtilis

\begin{tabular}{|c|c|c|c|c|}
\hline \multirow[t]{2}{*}{ Strain } & \multirow[t]{2}{*}{ oid } & \multirow[t]{2}{*}{$\mathbf{t}_{1} \mathbf{t}_{2}$} & \multicolumn{2}{|c|}{$\beta$-Galactosidase activity (Miller units) } \\
\hline & & & -IPTG & + IPTG \\
\hline HVS320† & & & $1 \cdot 3( \pm 0.7)$ & $1 \cdot 2( \pm 0 \cdot 6)$ \\
\hline +pMUTIN 1 & - & - & $9( \pm 2)$ & $1266( \pm 80)$ \\
\hline + pMUTIN 2 & - & + & $2 \cdot 2( \pm 0 \cdot 3)$ & $926( \pm 126)$ \\
\hline+ pMUTIN 3 & + & - & $4.5( \pm 0.35)$ & $901( \pm 36.5)$ \\
\hline +pMUTIN 4 & + & + & $1 \cdot 2( \pm 1 \cdot 1)$ & $433( \pm 17)$ \\
\hline
\end{tabular}

* $\beta$-Galactosidase activity was measured in at least two experiments; the results are shown as means $\pm S D$.

†HVS320 cells were harvested after growth in rich medium without IPTG ( - IPTG) or in the presence of $1 \mathrm{mM}$ IPTG (+ IPTG) at $\mathrm{OD}_{600} 0 \cdot 5$.
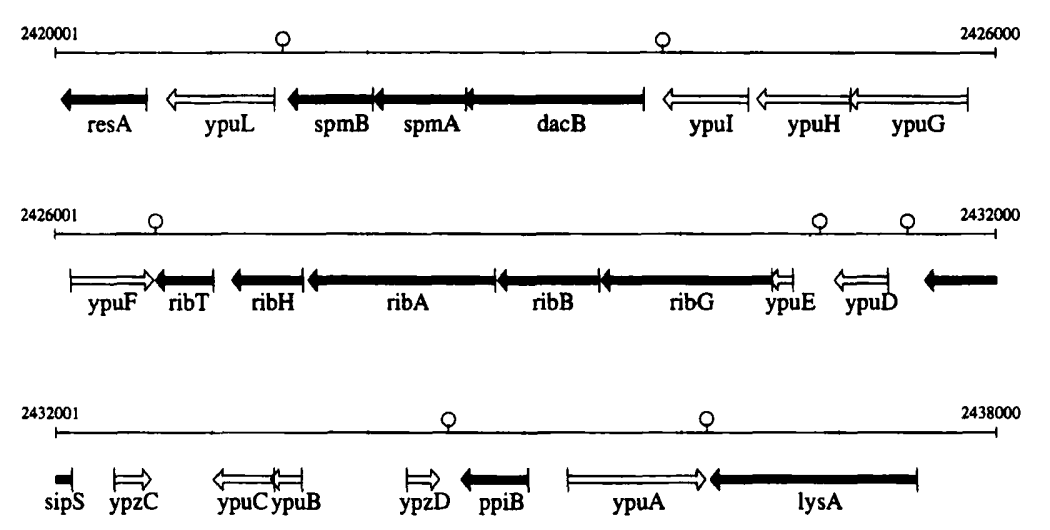

Fig. 4. Physical map of the resA-lysA region of the $B$. subtilis chromosome, from MICADO database (http://locus.jouy.inra.fr/ Micado). $y p z C$ and $y p z D$ ) were too short to be considered (respectively 154, 201, 237 and $213 \mathrm{bp}$ ). In one case, $y p u D$, a small gene (345 bp), was put under Pspac control. Four of the seven genes for which disruption was attempted were disrupted by integration of pMUTIN1: $y p u A, C, F$ and I (Fig. 4). It was not possible to obtain any transformants by integration of pMUTIN within $y p u G, y p u H$ and $y p u L$. We observed that efficiencies of transformation varied almost linearly from $10^{3}$ to $10^{5}$ transformants per $\mu \mathrm{g}$ DNA with $150-300 \mathrm{bp}$ of homology (data not shown). As the length of homology was within this range for these mutants, we assume that these genes might be essential, and they were consequently put under the control of Pspac. For this purpose, pMUTIN2 was inserted in front of the RBS of the gene, preserving a functional gene after integration.

Growth curves in rich and minimal media performed with all the mutants did not reveal any difference from the wild-type strain 168 with respect to growth rate and yield (data not shown). All the strains were able to sporulate on plates. The activities of their respective promoters were tested by measuring $\beta$-galactosidase activities (Table 3). $y p u I$ and $y p u G, H$ are better expressed in rich than in minimal medium, whereas $y p u F$ and $y p u A$ are expressed better in minimal medium. Only weak activities were observed for $y p u C, y p u D$ and $y p u L$ in each medium. These results are in agreement
Table 3. $\beta$-Galactosidase activity from the natural promoters of seven genes with no known function after integration of PMUTIN2

$\beta$-Galactosidase activities are expressed in Miller units (mg protein) ${ }^{-1}$. L1, L2 and L3 indicate different stages of growth: $\mathrm{L} 1, \mathrm{OD}_{600} 0 \cdot 2 ; \mathrm{L} 2, \mathrm{OD}_{600} 0 \cdot 6 ; \mathrm{L} 3, \mathrm{OD}_{600} 2 \cdot 5 . \mathrm{M} 1$ indicates minimal medium in exponential phase and $\mathrm{M} 2$ at stationary phase.

\begin{tabular}{|lrrrrr|}
\hline Strain & L1 & L2 & L3 & M1 & M2 \\
\hline$y p u A$ & 80 & 150 & 100 & 200 & 350 \\
$y p u C$ & 2 & 6 & 12 & 10 & 10 \\
$y p u D$ & 15 & 17 & 20 & 5 & 7 \\
$y p u F$ & 15 & 27 & 32 & 50 & 70 \\
$y p u G H$ & 600 & 600 & 150 & 100 & 75 \\
$y p u I$ & 150 & 300 & 150 & 60 & 80 \\
$y p u L$ & 11 & 31 & 26 & 15 & 25 \\
\hline
\end{tabular}

with RNA analysis (Azevedo et al., 1993), except that no RNA was detected for $y p u A$ and $y p u G, H$ at the early exponential phase and at the stationary phase in rich medium. This failure could be due either to the stability of the LacZ protein accumulated in the cells, or to the instability of the mRNAs during the stationary phase. 
$y p u C$, for which a weak level of $\beta$-galactosidase was found, seems to be better expressed during sporulation.

We were unable to disrupt $y p u G$ and $y p u H$. Insertion of pMUTIN in front of the operon was possible only when IPTG was added to the medium. This IPTG dependence during transformation indicates that the operon contains at least one essential gene.

To investigate the properties of $y p u G, H$, a further shiftdown experiment was carried out, in which the behaviour of the cells was studied when IPTG was removed from the medium. As a control, $d n a C$, which encodes a helicase essential for chromosome replication, was placed under the control of the Pspac promoter by integration of pMUTIN2 in the chromosome. In both strains, cell viability started to decrease about $2 \mathrm{~h}$ after withdrawal of IPTG (Fig. 5). Microscope analysis at $3 \mathrm{~h}$ revealed the presence of filamented cells. Since RNA analysis showed an undetectable level of mRNA $10 \mathrm{~min}$ after IPTG removal (data not shown), we assumed that the $2 \mathrm{~h}$ delay before the c.f.u. decrease was due to the protein half-life in cells.

\section{Concluding remarks}

The gene inactivation vectors described in this work were constructed to study $B$. subtilis genes with unknown function. Their main advantages are that they allow the rapid construction of insertional mutants, which can be used for a number of phenotype tests, facilitating the search for the target-gene function. All the vectors also allow the polar effects of the insertion of the vector to be avoided, as when the target gene is not in a monocistronic operon, or in the last position of a multicistronic operon. Such effects could otherwise render it difficult to correlate the phenotype with the inactivation of the target gene. Furthermore, some vectors (i.e. pMUTIN2 and pMUTIN4) facilitate the construction of conditional mutants, which is important for studies of genes essential for cell survival. One of the main drawbacks of these vectors is that the single crossover insertions require a minimum length of homology between the vector and the target gene. Although it has been previously suggested that $70 \mathrm{bp}$ is sufficient for homologous recombination (Khasanov et al., 1992), in our hands, at least $150 \mathrm{bp}$ homology is necessary to obtain plasmid integration. It is therefore not possible to inactivate genes shorter than about $250 \mathrm{bp}$ by internal insertion and, even for longer genes, the insertion cannot modify the 70 aa $\mathrm{N}$-terminal domain of their products. Such a domain could have an activity that obscures the mutant phenotype. However, since it is possible to control the expression of the genes by withdrawal of the inducer, this drawback is not prohibitive, except for very short genes, for which a deletion by double crossing-over integration of a resistance cassette can be proposed.

A further development of the insertional vectors that allow systematic inactivation of individual genes can be contemplated, in response to two features of the $B$. subtilis genome. One is the possibility that an operon
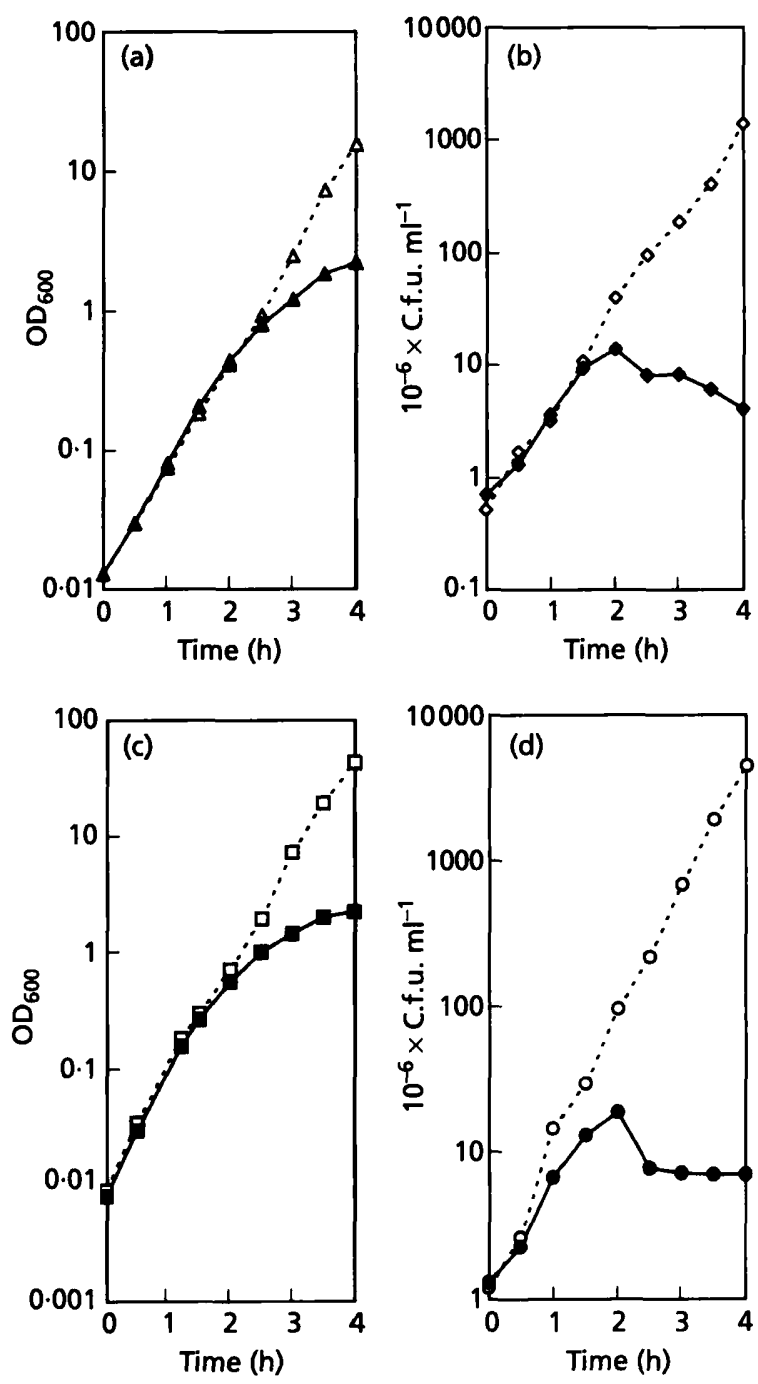

Fig. 5. Viability of dnaC (HVS597, a, b) and ypuG,H (c, d) mutants. The corresponding genes were put under the control of the Pspac promoter. Cells were grown in rich medium with $1 \mathrm{mM}$ IPTG, centrifuged and rinsed twice, then resuspended in LB medium with $1 \mathrm{mM}$ IPTG (open symbols) or without IPTG (filled symbols). Cell growth was followed by $O D_{600}$ measurement $(a, c)$ or by colony counting after plating on IPTGcontaining medium $(b, d)$.

contains more than one essential gene, another is that there are homologous genes (paralogues) which may have overlapping functions (Kunst et al., 1997). A vector with features similar to that of the pMUTIN series, but having no homology with pMUTIN, would allow an additional gene to be inactivated, and thus study cases of two essential genes in the same operon, or two functionally related paralogues. Such a vector is presently being developed and should allow the study of most of the essential genes present in the same operon, since the average $B$. subtilis operon contains only about three genes (Kunst et al., 1997). It is unlikely that an analogous systematic approach would be practical for homologous genes of overlapping function that are present in more than two copies. 
In conclusion, the vectors described here have already been used to construct some 800 mutants within the network of European laboratories and about as many within a similar network in Japan (N. Ogasawara, personal communication). Generating a collection of isogenic mutants in most of the uncharacterized $B$. subtilis genes could be the final outcome of this effort.

\section{ACKNOWLEDGEMENTS}

We thank C. Anagnostopoulos and L. Jannière for critical comments on the manuscript. We thank P. Stragier and E. Maguin for providing pDG148 and pVE6023 vectors, and F. Chedin for the gift of p602/22T2 and primers. This work was supported by EU grant no. BIO4-CT95-0278.

\section{REFERENCES}

Anagnostopoulos, C. \& Spizizen, J. (1961). Requirements for transformation in Bacillus subtilis. J Bacteriol 81, 741-746.

Azevedo, V., Sorokin, A., Ehrlich, S. D. \& Serror, P. (1993). The transcriptional organization of the Bacillus subtilis 168 chromosome region between the spoVAF and serA genetic loci. Mol Microbiol 10, 397-405.

Barilla, D., Caramori, T. \& Galizzi, A. (1994). Coupling of flagellin gene transcription to flagellar assembly in Bacillus subtilis. $J$ Bacteriol 176, 4558-4564.

Birnboim, H. C. \& Doly, J. (1979). A rapid alkaline extraction procedure for screening recombinant plasmid DNA. Nucleic Acids Res 7, 1513-1523.

Chang, Y. C., Kadokura, H., Yoda, K. \& Yamasaki, M. (1996). Secretion of active subtilisin $\mathrm{YaB}$ by a simultaneous expression of separate pre-pro and pre-mature polypeptides in Bacillus subtilis. Biochem Biophys Res Commun 219, 463-468.

Doolittle, R. (1998). Microbial genomes opened up. Nature 392, 339-342.

Khasanov, F. K., Zvingila, D. J., Zainullin, A. A., Prozorov, A. A. \& Bashkirov, V.I. (1992). Homologous recombination between plasmid and chromosomal DNA in Bacillus subtilis requires approximately 70 bp of homology. Mol Gen Genet 234, 494-497.

Kumar, V., Fonstein, M. \& Haselkorn, R. (1996). Bacterium genome sequence. Nature 381, 653-654.

Kunst, F., Ogasawara, N., Moszer, I. \& 148 other authors (1997). The complete genome sequence of the gram-positive bacterium Bacillus subtilis. Nature 390, 249-256.

Lehming, N., Sartorius, J., Niemoller, M., Genenger, G., WilckenBergmann, B. \& Muller-Hill, B. (1987). The interaction of the recognition helix of lac repressor with lac operator. EMBO J 6, $3145-3153$.

Link, A. J., Phillips, D. \& Church, G. M. (1997). Methods for generating precise deletions and insertions in the genome of wildtype Escherichia coli: application to open reading frame characterization. J Bacteriol 179, 6228-6237.

Lu, Y., Turner, R. J. \& Switzer, R. L. (1995). Roles of the three transcriptional attenuators of the Bacillus subtilis pyrimidine biosynthetic operon in the regulation of its expression. J Bacteriol 177, 1315-1325.

Miller, J. H. (1972). Experiments in Molecular Genetics. Cold Spring Harbor, NY: Cold Spring Harbor Laboratory.
Msadek, T., Kunst, F., Henner, D., Klier, A., Rapoport, G. \& Dedonder, R. (1990). Signal transduction pathway controlling synthesis of a class of degradative enzymes in Bacillus subtilis: expression of the regulatory genes and analysis of mutations in degS and degU. J Bacteriol 172, 824-834.

Oehler, S., Amouyal, M., Kolkhof, P., von Wilcken-Bergmann, B. \& Muller-Hill, B. (1994). Quality and position of the three lac operators of $E$. coli define efficiency of repression. EMBO J13, 3348-3355.

Oliver, S. (1996). A network approach to the systematic analysis of yeast gene function. Trends Genet 12, 241-242.

Perego, M. (1993). Integrational vectors for genetic manipulation in B. subtilis. In Bacillus subtilis and Other Gram-positive Bacteria, pp. 615-624. Edited by A. L. Sonenshein, J. A. Hoch \& R. Losick. Washington, DC: American Society for Microbiology.

Perkins, J. B. \& Youngman, J. C. (1986). Construction and properties of Tn917-lac, a transposon derivative that mediates transcriptional gene fusions in Bacillus subtilis. Proc Natl Acad Sci USA 83, 140-144.

Peschke, U., Beuk, V., Bujard, H., Gentz, R. \& Le Grice, S. (1985). Efficient utilization of Escherichia coli transcriptional signals in Bacillus subtilis. J Mol Biol 186, 175-182.

te Riele, H., Michel, B. \& Ehrlich, S. D. (1986). Single stranded plasmid DNA in Bacillus subtilis and Staphylococcus aureus. Proc Natl Acad Sci USA 83, 2541-2545.

Scholtissek, S. \& Grosse, F. (1987). A cloning cartridge of $\lambda t_{0}$ terminator. Nucleic Acids Res 15, 3185.

Shoemaker, D. D., Lashkari, D. A., Morris, D., Mittmann, M. \& Davis, R. W. (1996). Quantitative phenotypic analysis of yeast deletion mutants using a highly parallel molecular bar-coding strategy. Nat Genet 14, 450-456.

Smith, V., Botstein, D. \& O'Brown, P. (1995). Genetic footprinting: a genomic strategy for determining a gene's function given its sequence. Proc Natl Acad Sci USA 92, 6479-6483.

Sorokin, A., Zumstein, E., Azevedo, V., Ehrlich, S. D. \& Serror, P. (1993). The organization of the Bacillus subtilis 168 chromosome region between the spoVA and serA genetic loci, based on sequence data. Mol Microbiol 10, 385-395.

Spradling, A. C., Stern, D. M., Kiss, I., Roote, J., Laverty, T. \& Rubin, G. M. (1995). Gene disruptions using $P$ transposable elements: an integral component of the Drosophila genome project. Proc Natl Acad Sci USA 92, 10824-10830.

Stragier, P., Bonamy, C. \& Karmazyn-Campelli, C. (1988). Processing of a sporulation sigma factor in Bacillus subtilis: how morphological structure could control gene expression. Cell 52, 697-704.

Straney, S. B. \& Crothers, D. M. (1987). Lac repressor is a transient gene-activating protein. Cell 51, 699-707.

Vagner, V. \& Ehrlich, S. D. (1988). Efficiency of homologous DNA recombination varies along the Bacillus subtilis chromosome. J Bacteriol 70, 3978-3982.

Voelker, U., Dufour, A. \& Haldenwang, W. G. (1995). The Bacillus subtilis $r s b U$ gene product is necessary for RsbX-dependent regulation of sigma B. J Bacteriol 177, 114-122.

Yansura, D. G. \& Henner, D. J. (1984). Use of the Escherichia coli lac repressor and operator to control gene expression in Bacillus subtilis. Proc Natl Acad Sci USA 81, 439-443.

Received 18 May 1998; revised 3 July 1998; accepted 9 July 1998. 